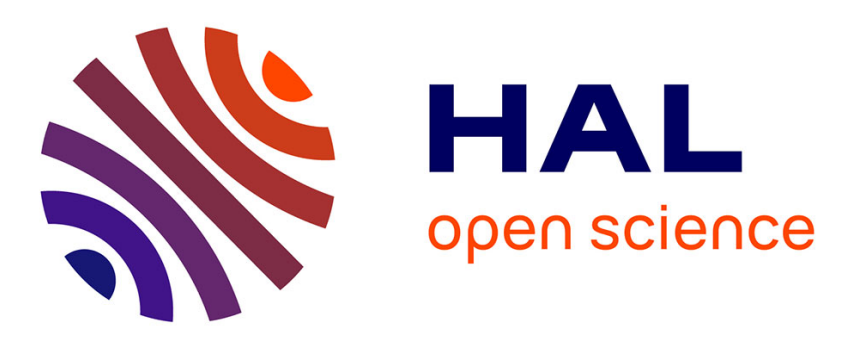

\title{
Contribution of multitemporal polarimetric synthetic aperture radar data for monitoring winter wheat and rapeseed crops
}

Julie Betbeder, Rémy Fieuzal, Yannick Philippets, Laurent Ferro-Famil, Frédéric Baup

\section{To cite this version:}

Julie Betbeder, Rémy Fieuzal, Yannick Philippets, Laurent Ferro-Famil, Frédéric Baup. Contribution of multitemporal polarimetric synthetic aperture radar data for monitoring winter wheat and rapeseed crops. Journal of applied remote sensing, 2016, 10 (2), pp.026020-026020. 10.1117/1.JRS.10.026020 . hal-01331288

\section{HAL Id: hal-01331288 \\ https://hal-univ-rennes1.archives-ouvertes.fr/hal-01331288}

Submitted on 20 Oct 2016

HAL is a multi-disciplinary open access archive for the deposit and dissemination of scientific research documents, whether they are published or not. The documents may come from teaching and research institutions in France or abroad, or from public or private research centers.
L'archive ouverte pluridisciplinaire HAL, est destinée au dépôt et à la diffusion de documents scientifiques de niveau recherche, publiés ou non, émanant des établissements d'enseignement et de recherche français ou étrangers, des laboratoires publics ou privés. 


\title{
Contribution of multitemporal polarimetric synthetic aperture radar data for monitoring winter wheat and rapeseed crops
}

\author{
Julie Betbeder, ${ }^{\text {a,* }}$ Remy Fieuzal, ${ }^{\text {a }}$ Yannick Philippets, ${ }^{\text {a,b }}$ \\ Laurent Ferro-Famil, ${ }^{\mathrm{c}}$ and Frederic Baup ${ }^{\mathrm{a}}$ \\ ${ }^{a}$ Université de Toulouse, Centre d'Etudes Spatiales de la Biosphère (CESBIO), UMR 5126 UPS- \\ CNES-CNRS-IRD 18 Avenue Edouard Belin, 24 rue d'Embaques, 32000 AUCH, France \\ ${ }^{b}$ Ecole Nationale des Sciences Géographiques (ENSG), 6-8 avenue Blaise Pascal, \\ Cité Descartes, Champs-sur-Marne, 77455 Marne-la-Vallée Cedex 2, France \\ ${ }^{c}$ Université de Rennes 1, IETR, Campus Beaulieu-bât 11D, 263, av du général Leclerc, \\ CS 74205, 35042 Rennes Cedex, France
}

\begin{abstract}
This paper aims to evaluate the contribution of multitemporal polarimetric synthetic aperture radar (SAR) data for winter wheat and rapeseed crops parameters [height, leaf area index, and dry biomass (DB)] estimation, during their whole vegetation cycles in comparison to backscattering coefficients and optical data. Angular sensitivities and dynamics of polarimetric indicators were also analyzed following the growth stages of these two common crop types using, in total, 14 radar images (Radarsat-2), 16 optical images (Formosat-2, Spot-4/5), and numerous ground data. The results of this study show the importance of correcting the angular effect on SAR signals especially for copolarized signals and polarimetric indicators associated to single-bounce scattering mechanisms. The analysis of the temporal dynamic of polarimetric indicators has shown their high potential to detect crop growth changes. Moreover, this study shows the high interest of using SAR parameters (backscattering coefficients and polarimetric indicators) for crop parameters estimation during the whole vegetation cycle instead of optical vegetation index. They particularly revealed their high potential for rapeseed height and DB monitoring [i.e., Shannon entropy polarimetry $\left(r^{2}=0.70\right)$ and radar vegetation index $\left(r^{2}=0.80\right)$, respectively].
\end{abstract}

Keywords: winter wheat; rapeseed; synthetic aperture radar; Radarsat-2; Formosat-2; Spot; temporal signatures; normalized difference vegetation index; leaf area index; crop height; dry biomass; polarimetry.

Paper 16032P received Jan. 12, 2016; accepted for publication Apr. 14, 2016; published online May 11, 2016.

\section{Introduction}

Land cover, land use dynamics, and general crop monitoring represent key variables involved in sustainable management of intensive agricultural landscapes. ${ }^{1}$ Crop monitoring traditionally consists in the estimation of surface parameters such as soil water content, crop height, leaf area index (LAI), or dry biomass (DB) throughout the vegetation cycle. These variables are very important as they are involved in future challenges, such as crop disease control, ${ }^{2}$ water resource management, ${ }^{3}$ or crop fertilizer applications. ${ }^{4}$ For example, they can be used as input parameters into crop models to simulate energy fluxes, water balance, biomass, or grain yield. ${ }^{3-6}$ However, when these models are applied over several fields at a landscape scale, input parameters, which are mostly acquired using accurate ground surveys, cannot be 
collected on such an area due to time requirements. ${ }^{7}$ Worldwide, the monitoring of these data requires tools capable of mapping large spatial extent, while keeping fine spatial resolution.

In this context, high spatial resolution (HSR) remotely sensed images offer a unique opportunity to accurately monitor cropland worldwide and to estimate crop parameters at a fine scale. Indeed, they can survey agro-systems at HSR over large areas, with medium to high temporal repetitiveness. Many studies demonstrated the interest of using optical reflectance and/or vegetation indices ${ }^{4,8}$ combined with models of culture ${ }^{6,7}$ to estimate crop parameters, such as DB, water content, or LAI. However, the acquisition of optical images is dependent on cloud-free periods and optical signal provides information on only the top layer of vegetation. Moreover, only the first crop phenological stages can be monitored using these wavelengths, since the signal saturates at high LAI levels. ${ }^{9}$

Now, HSR microwave images provide a reliable alternative to optical time series since they are not significantly affected by atmospheric conditions and can be acquired during the day or night. In contrast to optical data, the backscattering signal acquired in the microwave domain mainly depends on soil conditions (e.g., roughness and moisture ${ }^{10-15}$ ) at the beginning of the vegetation cycle and then on crop properties when the vegetation is sufficiently developed (e.g., DB, architecture, height ${ }^{1,16-19}$ ). Some studies have successfully demonstrated the potential of backscattering coefficients derived from SAR time series to monitor vegetation parameters of different crop types such as wheat, rapeseed, or sugarcane using copolarized $\left(\sigma_{\mathrm{HH}}^{\circ}, \sigma_{\mathrm{VV}}^{\circ}\right)$ or cross-polarized backscattering coefficients $\left(\sigma_{\mathrm{HV}}^{\circ}\right) \cdot{ }^{10,17,20-22}$

During the recent years, these approaches started to be completed by those dealing with the use of polarimetric indicators for crop parameters estimations. Polarimetric data provide interesting information about polarization amplitude and phase, allowing the identification of the backscattering mechanisms (i.e., single-bounce, double-bounce, or volume scattering) induced by the observed target properties. Most of the studies aiming to evaluate the sensitivity of polarimetric indicators derived from SAR time series to crop parameters were focused on data acquired at C-band spaceborne (Radarsat-2) or airborne ones. ${ }^{11,23}$ The SAR sensor system onboard Radarsat-2 is actually the only one able to provide full polarimetric data from space with a quite low repetitiveness (repeat cycle $=24$ days), inadequate for crop parameters estimation like LAI, DB, or water content. Several SAR indicators can be extracted from full-polarization images,${ }^{24}$ to better identify changes in canopy structure and/or phenology of crops. ${ }^{19,25-29}$ However, although more and more studies investigate the contribution of PolSAR images for crop monitoring (e.g., maize, corn, soybean, wheat, rapeseed, rice), multitemporal and multiangular approaches remain infrequent and do not provide an overview of the potential of polarimetric indicators throughout the entire crop vegetation cycle. This information is nonetheless essential for crop yield monitoring using the assimilation of SAR data into crop models. ${ }^{30-32}$

Thus, in the context of current and upcoming space missions, such as Radarsat constellation, Sentinel-1 A/B, or Sentinel-2, the objective of this study is to investigate the contribution of multitemporal polarimetric indicators to estimate crop parameters during the whole vegetation cycle, at a fine scale through the analysis of angular sensitivity and backscattering mechanisms dynamics. To increase the repetitiveness of the SAR acquisitions during the vegetation cycle, an angular normalization method developed by Fieuzal et al. ${ }^{17}$ was applied. This method allows to correct the angular effect on SAR time series, acquired with higher repetitiveness than the satellite orbital cycle and thus with different incidence angles. This study focuses more particularly on two crop types: winter wheat and rapeseed, which represent two of the most important seasonal crops of the world in terms of occupied area (FAO, 2010). The target crop parameters correspond to crop height, crop LAI, and crop DB since they can be assimilated into crop models ${ }^{5-7,33-35}$ to estimate, for instance, crop production, ${ }^{5}$ crop evapotranspiration, ${ }^{36}$ or water needs ${ }^{3}$ over wide expanses.

The paper is structured as follows: study site and collected data (ground and SAR) are first presented in Sec. 2, followed by the description of the method in Sec. 3. Section 4 is divided into three parts, respectively, associated to (1) the angular normalization of SAR signals, (2) the analysis of the scattering mechanisms, and (3) the estimation of crop parameters using SAR polarimetric signals and optical vegetation index. Finally, global conclusions and perspectives are provided in Sec. 5 . 


\section{Study Site and Data Collection}

\subsection{Site Description}

The investigated area is a part of a French observatory, named Regional Spatial Observatory, labeled by the CNRS in $2007 .{ }^{37}$ It is located in the southwest of France (centered on the coordinates $43^{\circ} 29^{\prime} 36^{\prime \prime} \mathrm{N}, 01^{\circ} 14^{\prime} 14^{\prime \prime} \mathrm{E}$ ) and is dedicated to study agrosystems by combining both in situ and observations from space. The study site is subject to a temperate climate, characterized by a marked seasonality. During the year 2010, the annual cumulative rainfall was close to $600 \mathrm{~mm}$ and the thermal amplitude was $\sim 20^{\circ} \mathrm{C}$ between winter and summer. Extreme mean values were observed during the months of January and July, with 3.5 and $22^{\circ} \mathrm{C}$, respectively. ${ }^{38}$ The site is highly anthropized and mainly comprises seasonal crops (56.8\%), grasslands $(32.1 \%)$, forests $(7.9 \%)$, and urban areas $(2.4 \%)$. Among the cultivated crop species, this work focused more particularly on winter wheat (defined as wheat in the following) and rapeseed, representing half of annual crops. All along the year 2010, regular satellite acquisitions were acquired synchronously with ground measurements, during the Multisensor Crop Monitoring experiment conducted by CESBIO. ${ }^{39}$ Fourteen fields of wheat and four of rapeseed were intensively monitored, respectively, averaging 10 and 9 ha in size (Fig. 1). The main characteristics of the collected data are presented in Secs. 2.2 and 2.3.

\subsection{Satellite Images}

During the crop vegetation cycles, a series of 14 quad-polarization Radarsat-2 images was acquired, together with 16 optical images (provided by Formosat-2, Spot-4/5 sensors) at HSR. $^{39}$ Radarsat-2 images were acquired in Fine-Quad-Pol mode, delivered with HH, VV, $\mathrm{HV}$, and VH polarization states and with incidence angles ranging from 24 to $41 \mathrm{deg}$. The associated range and azimuth spatial resolutions were, respectively, equal to 5.4 and $8.0 \mathrm{~m}$. The optical images were acquired with a spatial resolution of 8, 20, and $10 \mathrm{~m}$ according to the sensor and a spectral resolution of 4 bands. More characteristics of the optical and radar images are summarized in Table 1.

\subsection{Field Surveys}

Synchronous to satellite acquisitions, ground surveys were conducted, respectively, on 14 and 4 fields of wheat and rapeseed (Fig. 1) in order to monitor agricultural practices (dates of sowing and harvesting), vegetation parameters (crop height and DB), phenological stages following the Biologische Bundesanstalt, Bundessortenamt and CHemical industry (BBCH) stages ${ }^{40}$ (Tables 2 and 3 for wheat and rapeseed, respectively), and soil parameters [top soil moisture (TSM) and surface roughness].

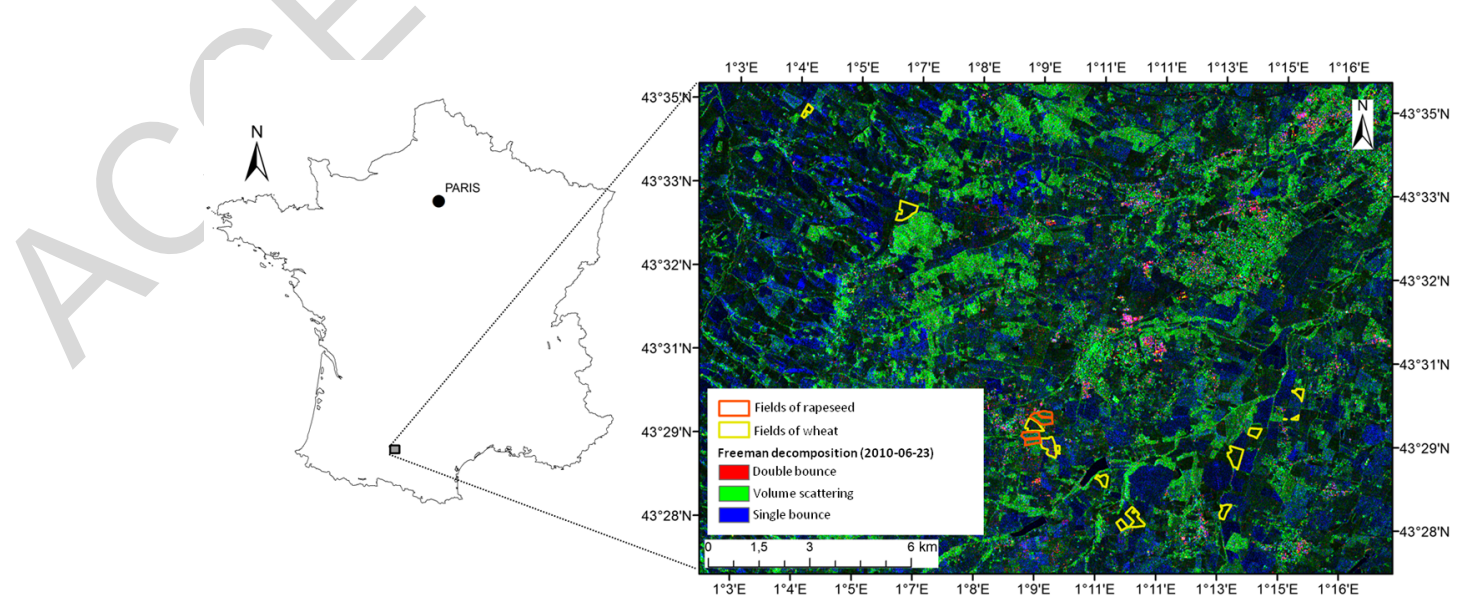


Betbeder et al.: Contribution of multitemporal polarimetric synthetic aperture radar...

Table 1 Characteristics of the satellite remote sensing data.

\begin{tabular}{|c|c|c|c|c|c|}
\hline \multirow[b]{3}{*}{ Dates } & \multirow{2}{*}{\multicolumn{2}{|c|}{$\begin{array}{c}\text { Radar images } \\
\text { Radarsat-2 }\end{array}$}} & \multicolumn{3}{|c|}{ Optical images } \\
\hline & & & \multirow{2}{*}{$\frac{\text { Spot-4 }}{\text { April 9, }}$} & \multirow{2}{*}{$\frac{\text { Spot-5 }}{\text { February } 18,}$} & \multirow{2}{*}{$\frac{\text { Formosat-2 }}{\text { March 2, } 2010}$} \\
\hline & February 20, & May 2, 2010 & & & \\
\hline & 2010 & May 9, 2010 & 2010 & 2010 & April 10, 2010 \\
\hline & February 26, & May 20, 2010 & May 10, & March 26, & April 18, 2010 \\
\hline & 2010 & May 30, 2010 & 2010 & 2010 & April 27, 2010 \\
\hline & March 5, & June 12,2010 & June 5 & March 26, & May 21,2010 \\
\hline & 2010 & June 23,2010 & 2010 & 2010 & July 7,2010 \\
\hline & March 16, & July 3, 2010 & June 26, & April 10, & \\
\hline & 2010 & & 2010 & 2010 & \\
\hline & March 26, & & July 1 , & P & \\
\hline & 2010 & & 2010 & & \\
\hline & April 8, 2010 & & & & \\
\hline & April 15, & & & & \\
\hline & 2010 & & & & \\
\hline $\begin{array}{l}\text { Ground spatial } \\
\text { resolutions }\end{array}$ & $\begin{array}{l}\text { Rang } \\
\text { Azim }\end{array}$ & $\begin{array}{l}5.4 \mathrm{~m} \\
\mathrm{~h}: 8 \mathrm{~m}\end{array}$ & & $10 \mathrm{~m}$ & $8 \mathrm{~m}$ \\
\hline \multirow{4}{*}{$\begin{array}{l}\text { Spectral, geometric, } \\
\text { and polarimetric } \\
\text { characteristics }\end{array}$} & C-band (5.5 & $\mathrm{n}, 5.405 \mathrm{GH}_{2}$ & \multicolumn{2}{|c|}{$\begin{array}{c}\text { B1: } 0.5 \text { to } 0.59 \mu \mathrm{m} \\
\text { (Green) }\end{array}$} & $\begin{array}{c}\text { B1: } 0.45 \text { to } 0.52 \mu \mathrm{m} \\
\text { (Blue) }\end{array}$ \\
\hline & Quad $p$ & larization & \multicolumn{2}{|c|}{ B2: 0.61 to $0.68 \mu \mathrm{m}$ (Red) } & $\begin{array}{c}\text { B2: } 0.52 \text { to } 0.60 \mu \mathrm{m} \\
\text { (Green) }\end{array}$ \\
\hline & $(\mathrm{HH} / \mathrm{V}$ & (HV/VH) & \multicolumn{2}{|c|}{ B3: 0.79 to $0.89 \mu \mathrm{m}$ (NIR) } & $\begin{array}{c}\text { B3: } 0.63 \text { to } 0.69 \mu \mathrm{m} \\
\text { (Red) }\end{array}$ \\
\hline & Fine-Qua & -Pol mode & \multicolumn{2}{|c|}{ B4: 1.58 to $1.75 \mu \mathrm{m}$ (MIR) } & $\begin{array}{c}\text { B4: } 0.76 \text { to } 0.90 \mu \mathrm{m} \\
\text { (NIR) }\end{array}$ \\
\hline
\end{tabular}

Table 2 Main $\mathrm{BBCH}$ phenological stages of wheat considered in this study.

\begin{tabular}{lc}
\hline \hline $\mathrm{BBCH}$ & BBCH phenological stages of wheat \\
\hline 10 to 20 & Leaf development \\
20 to 30 & Tillering \\
30 to 40 & Stem elongation \\
40 to 50 & Booting \\
50 to 60 & Inflorescence emergence, heading \\
60 to 70 & Flowering, anthesis \\
70 to 80 & Development of fruit \\
80 to 90 & Ripening \\
90 to 100 & Senescence \\
\hline \hline
\end{tabular}


Table 3 Main $\mathrm{BBCH}$ phenological stages of rapeseed considered in this study.

\begin{tabular}{ll}
\hline \hline BBCH & BBCH phenological stages of rapeseed \\
\hline 10 to 30 & Leaf development \\
30 to 40 & Formation of side shoots \\
40 to 50 & Stem elongation \\
50 to 60 & Inflorescence emergence \\
60 to 70 & Flowering \\
70 to 80 & Development of fruit \\
80 to 90 & Ripening \\
90 to 100 & Senescence \\
\hline \hline
\end{tabular}

DB measurements were performed in two fields of wheat and one of rapeseed. For each field, five samples of $50 \mathrm{~cm}$ length were collected in homogeneous areas $\left(20\right.$ by $\left.20 \mathrm{~m}^{2}\right)$. Wet biomass was directly estimated in situ, whereas DB was measured after crop drying (oven, $65^{\circ} \mathrm{C}, 48 \mathrm{~h}$ ). Figure 2 shows the temporal dynamics of DB together with the crop height. The wheat plant height ranged from 0.1 to $0.8 \mathrm{~m}$ (maximal value was reached at day 140, before the head maturation) and the DB ranged from 35 to $2100 \mathrm{~g} \cdot \mathrm{m}^{-2}$ between the sowing and harvest dates. The rapeseed plant height ranged from 0.2 to $1.8 \mathrm{~m}$ (maximal value reached at day 120 , before the development of pods) and the DB ranged from 40 to $2200 \mathrm{~g} \cdot \mathrm{m}^{-2}$.

TSM measurements $(5 \mathrm{~cm}$ depth) were collected along transects using a mobile Theta-probes sensor (ML2x) (the mean TSM was calculated from at least 15 measurements for each field). Each measure was normalized (\% volumetric or $\mathrm{m}^{3}$ by $\mathrm{m}^{-3}$ ) using a calibration relationship established by Baup et al. ${ }^{39}\left(r^{2}\right.$ mean $\left.=0.75\right)$. TSM variations were inferior to $5 \%$ vol. between all 14 wheat fields for each acquisition date and inferior to 3.5\% vol. between the four rapeseed fields. Surface roughness was collected along and perpendicular to the row direction on the 18 fields, after crop sowing. The root mean square height $\left(h_{\mathrm{rms}}\right)$ and correlation length $(\mathrm{lc})$ were derived from $4 \mathrm{~m}$ roughness profiles. Surface roughness was small and stable in time since no tillage event occurred after the crop sowing. The soil roughness of fields cultivated with wheat had the following features: mean $h_{\mathrm{rms}}=10.0 \mathrm{~mm}$ and mean $\mathrm{lc}=71.2 \mathrm{~mm}$. Concerning the fields of rapeseed, the mean $h_{\text {rms }}$ was equal to $10.1 \mathrm{~mm}$ and the mean lc was equal to $69.2 \mathrm{~mm}$. Textural measurements were also conducted on the top soil layer of the monitored fields using core samples $(25 \mathrm{~cm}$ depth). The wheat fields were classified into three textural classes of the textural triangle HYPRES ${ }^{41}$ (as defined by the European Soil Map): medium, medium fine, and fine, and rapeseed fields into two textural classes: medium and medium fine.
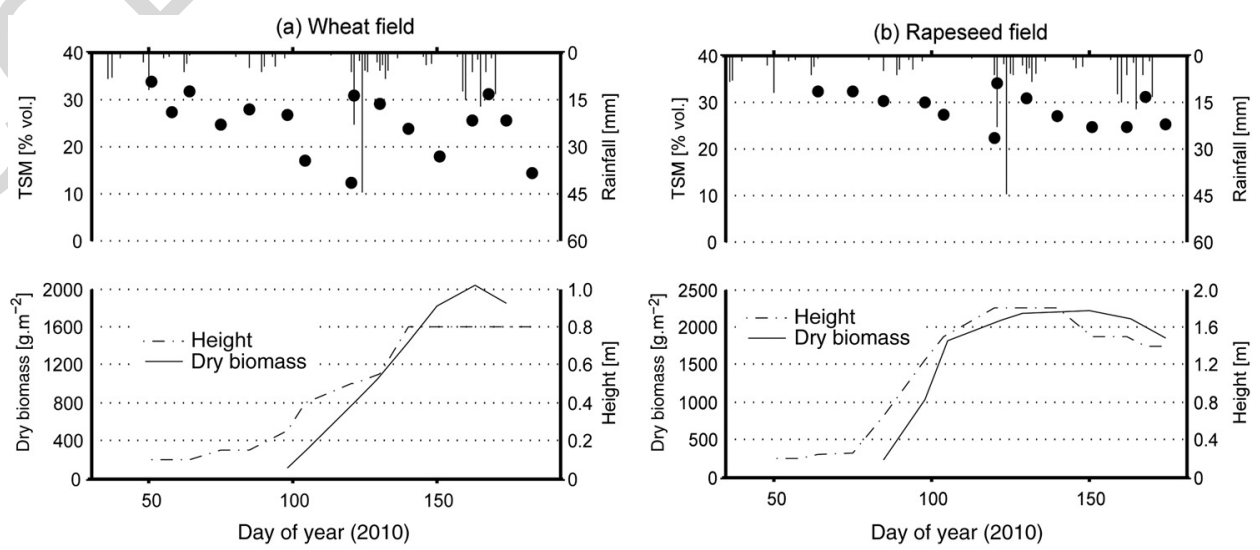

Fig. 2 Temporal dynamics of TSM (\% vol.], rainfall $(\mathrm{mm})$, crop height $(\mathrm{m})$, and dry biomass $\left(\mathrm{g} \cdot \mathrm{m}^{-2}\right.$ ] observed over one field of $(\mathrm{a})$ wheat and $(\mathrm{b})$ rapeseed. 


\section{Methodology}

The method used to analyze the multitemporal polarimetric indicators acquired throughout the wheat and rapeseed agricultural season, through the analysis of backscattering mechanism involved to the total signal and of the sensitivity to crop parameters, is describe on Fig. 3. The first step consisted in preprocessing time series of optical (i.e., atmospheric and geometric corrections-Sec. 3.1) and SAR (i.e., geometric corrections, radar signal calibration, polarimetric indicators extraction-Sec. 3.2) signals. According to Fieuzal et al., ${ }^{17}$ an angular correction was then applied to the SAR parameters to subtract the effect of incidence angle on C-band data (Sec. 3.3). SAR and optical signals were finally obtained by averaging all pixels at field scale. Then, the normalized SAR backscattered dynamics were qualitatively analyzed to study the scattering mechanisms involved during wheat and rapeseed phenological cycles. Nonlinear regressions [Eq. (1)] were finally established between the SAR or optical parameters [defined as remote sensing indicator (RSI)] and the measured ground variables including vegetation height, DB, and LAI.

$$
\mathrm{CP}=a \times e^{(b \times \mathrm{RSI})}+c,
$$

where CP corresponds to the crop parameter (LAI, DB, or height) and RSI to the remote sensing indicator [polarimetric indicators, backscattering coefficients, or normalized difference vegetation index (NDVI)].

The best indicator for each crop parameter estimation was selected based on the coefficient of determination $\left(r^{2}\right)$ and relative root mean square error (rRMSE) values.

\subsection{Optical Images Processing}

Optical images were corrected from atmospheric perturbations, ${ }^{42}$ ortho-rectified (accuracy less than 1/2 pixel) and geo-referenced based on the Lambert 93 reference system, using the Centre National d'Etudes Spatiales (CNES) processing chain. ${ }^{43}$ Two vegetation indices were derived from the optical images (Fig. 3): the well-known NDVI and the modified triangular vegetation index (MTVI2), ${ }^{9}$ which is calculated by using the reflectance in near-infrared, red, and green. NDVI was used in the angular correction step and to compare to SAR indicators for height and DB estimations. MTVI2 was used to derive LAI (Ref. 44) since the robustness of this vegetation

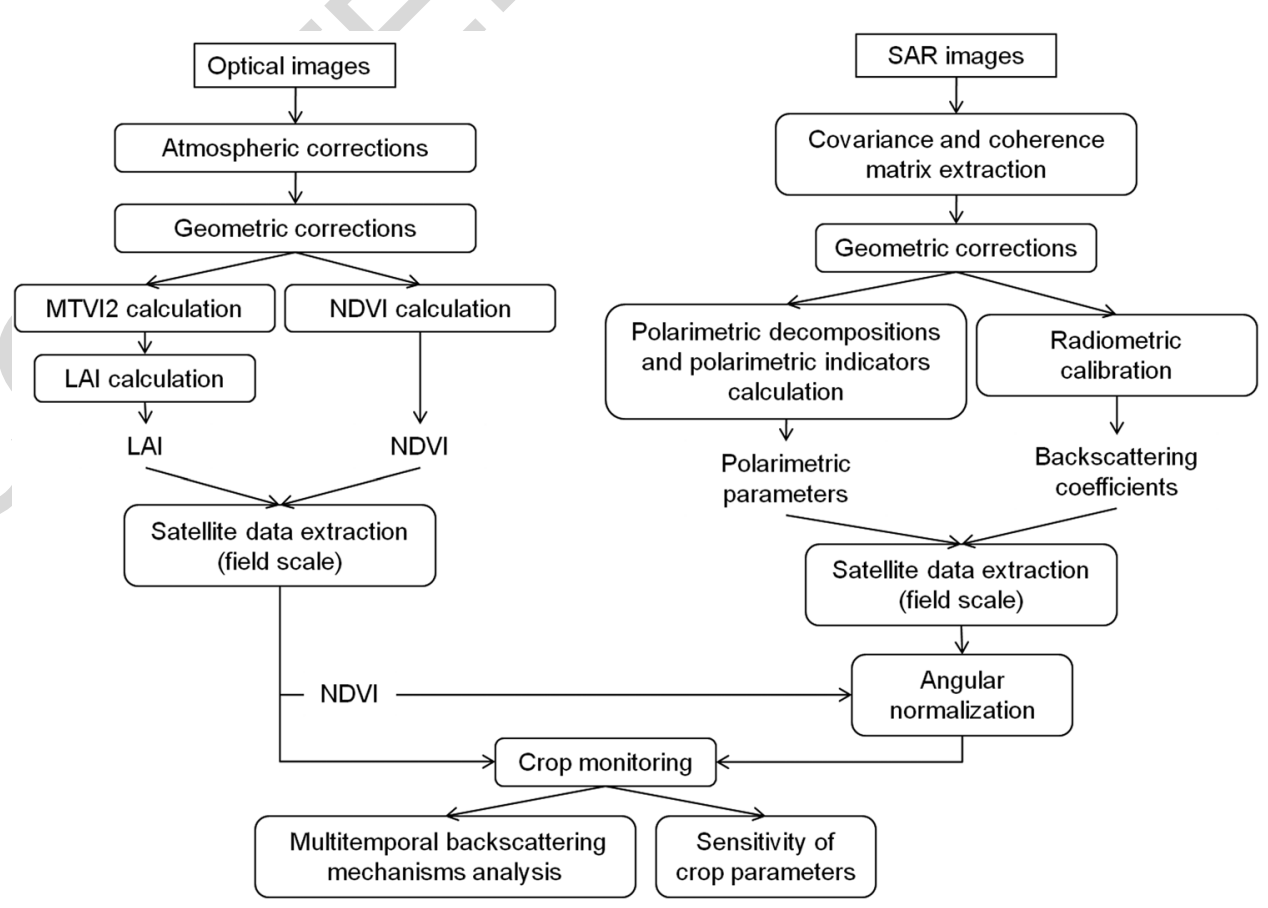

Fig. 3 Workflow of spaceborne data set processing and signal analysis. 
index was demonstrated in a lot of previous studies $\left(r^{2}>\sim 0.8\right)^{25,44,45}$ [Eq. (2)]. NDVI was not compared to LAI since these data were derived from the same optical time series and thus were linearly correlated $\left(r^{2} \geq 0.9\right)$.

$$
\mathrm{LAI}=-6.247 \times \ln (0.943-0.643 \times \mathrm{MTVI} 2) .
$$

NDVI and LAI values derived from the three optical sensors (Formosat-2, Spot-4/5) were merged into the same temporal profile because no bias has been observed. ${ }^{17}$ These values were daily interpolated to match with the date of SAR acquisition. LAI values were consistent with LAI values derived from hemispherical photographs on wheat and rapeseed over same temperate climate. ${ }^{46-48}$

\subsection{Synthetic Aperture Radar Image Preprocessing}

Radarsat-2 images were first radiometrically calibrated to extract the backscattering coefficients: $\sigma_{\mathrm{HH}}^{\circ}, \sigma_{\mathrm{VV}}^{\circ}$, and $\sigma_{\mathrm{HV}}^{\circ}$, according to the following equation: ${ }^{49}$

$$
\sigma^{\circ}(\mathrm{dB})=20 \times \log _{10}\left(\frac{\mathrm{DN}_{i}}{A 2_{i}}\right)+10 \times \log _{10}\left[\sin \left(\theta_{i}\right)\right] .
$$

This equation transforms the digital number of each pixel (DN) into a backscattering coefficient on a decibel scale, using the gain $(A 2)$ and the radar incidence angle $(\theta)$.

The images were then geo-coded using the Shuttle Radar Topography Mission data to correct the topographic deformations (geometric correction accuracy $<1$ pixel) and projected into the Lambert-RGF93/IGN-69 system (Fig. 3). There were additionally three intensity ratio channels produced (HH/VV, VV/HV, HH/HV) from the backscattering coefficient images.

In addition, 17 polarimetric indicators were extracted from each of the SLC Radarsat-2 image. $(3 \times 3)$ coherency matrices $(\mathrm{T} 3)$ were first extracted from the scattering matrix images S using the Pauli spin basis $k_{T}$ (Ref. 24) (Fig. 3) on PolSARpro v5.0 software (Polarimetric SAR Data Processing and Educational Toolbox $).{ }^{50}$ The geo-coding process was directly applied to the elements of the T3 matrices, which are independent of the polarimetric absolute phase. ${ }^{23}$ The first, T11 $\left\langle\left|S_{\mathrm{HH}}+\mathrm{S}_{\mathrm{VV}}\right|^{2}\right\rangle$, second, T22 $\left\langle\left|\mathrm{S}_{\mathrm{HH}}-\mathrm{S}_{\mathrm{VV}}\right|^{2}\right\rangle$, and third, T33 $4\left\langle\left|\mathrm{~S}_{\mathrm{HV}}\right|^{2}\right\rangle$, elements of the diagonal were used to study single-bounce, double-bounce, and volume scattering mechanisms, respectively.

Both Cloude-Pottier ${ }^{51}$ and Freeman-Durden ${ }^{52}$ decompositions were also performed on the complex Radarsat-2 matrices. Cloude-Pottier (or eigenvector-eigenvalue) decomposition is based on the eigen decomposition of the coherency matrix (T3) into three matrices associated to orthogonal scattering mechanisms. Each of them denotes a scattering mechanism described by an eigenvector $u_{i}$, and an intensity associated to the corresponding eigenvalue $\lambda_{i}$. In order to analyze the physical information provided by the Cloude-Pottier decomposition, three parameters were derived: entropy $(H)$, which expresses the randomness of the polarimetric scattering process, alpha angle $(\alpha)$, which describes the mean scattering mechanism, and anisotropy $(A)$, which represents the relative power of the second and third eigenvectors. Freeman-Durden decomposition is used to model the T3 matrix as the sum of three scattering mechanisms for each pixel: the volume scattering (Freeman VOL), which generally reflects a complex vegetation canopy (randomly oriented dipoles), the double-bounce scattering (Freeman DB), which is characteristic of the incident wave interaction between a flat surface and a vertical object (dihedral corner reflector), and the surface or single-bounce scattering (Freeman SB), which corresponds to a flat or slightly rough surface.

Other polarimetric indicators that have also shown promising sensitivity to the vegetation growth were also extracted: SPAN, which corresponds to the total scattered power, ${ }^{24}$ Shannon entropy (SE), which corresponds to the sum of two contributions related to the intensity (SEi) and the degree of polarization (SEp) for each pixel, ${ }^{24}$ and the radar vegetation index (RVI). ${ }^{26}$

Finally, the following 17 polarimetric indicators were analyzed: entropy, anisotropy, alpha angle, and eigenvalues $\left(\lambda_{1}, \lambda_{2}, \lambda_{3}\right)$ (Cloude-Pottier decomposition), double-bounce, volume, and surface scattering (Freeman-Durden decomposition), SE, SEi, SEp, SPAN, RVI, and T11, T22, and T33. 


\subsection{Multiangular Synthetic Aperture Radar Data Processing}

Previous studies have shown the strong influence of incidence angle on SAR responses during particular crop stages for contrasted soil conditions. ${ }^{11,12}$ To minimize the angular effect and increase the amount of observations offered by the initial Radarsat-2 orbital cycle (26 days), the backscattering coefficients and polarimetric indicators have been angular-normalized following the procedure developed by Fieuzal et al. ${ }^{17}$ Empirical relationships were established between the NDVI values and the backscattering coefficients or the polarimetric indicators differences estimated from two successive angular-contrasted images [Eq. (4)].

$$
\Gamma y_{\mathrm{SAR}}(\mathrm{NDVI})=\frac{y_{\mathrm{SAR}}\left(t_{2}\right)-y_{\mathrm{SAR}}\left(t_{1}\right)}{\theta\left(t_{2}\right)-\theta\left(t_{1}\right)}=\frac{\Delta y_{\mathrm{SAR}}}{\Delta \theta}=a \times e^{(b \times \mathrm{NDVI})}+c,
$$

where $\Gamma y_{\text {SAR }}$ corresponds to the difference in backscattering coefficients or polarimetric indicators between two successive angular-contrasted radar acquisition dates $\left(\Delta y_{\mathrm{SAR}}\right)$ divided by the difference of their incidence angle $(\Delta \theta)$. NDVI corresponds to the mean NDVI derived from optical images calculated between the SAR acquisitions. $a, b$, and $c$ represent empirical parameters of the relationship.

The selected images were the closest in time (to minimize disturbances from surface changes ${ }^{17}$ ) and with the largest gap relative to the incidence angle (to maximize the effect of the incidence angle). All the selected image pairs showed an incidence angle difference of at least $14 \mathrm{deg}$ (between acquisitions at 26 and $40 \mathrm{deg}$ ) and a maximum time interval of 13 days. Moreover, the difference in topsoil moisture between the pairs of images was lower than $4 \%$ vol.

Finally, the angular-normalized backscattering coefficients or polarimetric indicators [noted $y_{\text {SAR-normalized }}$ in Eq. (5)] were calculated for each radar acquisition as follows:

$$
y_{i, \mathrm{SAR}-\mathrm{normalized}}=y_{i, \mathrm{SAR}}+\Delta y_{i, \mathrm{SAR}},
$$

where

$$
\Delta y_{i, \mathrm{SAR}}=\left(\theta_{i}-\theta_{\mathrm{ref}}\right) \times \Gamma y_{\mathrm{SAR}}(\mathrm{NDVI}),
$$

where $\theta_{i}$ and $\theta_{\text {ref }}$ correspond to the incidence angle of the radar image and the reference incidence angle, respectively.

SAR signals were angular-normalized at $38.7 \mathrm{deg}$ to compare the results obtained in this study with other analyses aiming to evaluate the potential of multifrequency SAR data (acquired or angular-normalized at $38.7 \mathrm{deg}$ ) for crops monitoring over the same study site. ${ }^{17}$

\section{Results}

Section 4 is divided into three parts. The first part presents the results about the SAR angular normalization (Sec. 4.1), the second part describes the scattering mechanisms over rapeseed and wheat involved in the total SAR backscatter all along the crop cycle (Sec. 4.2), and the last part presents the results about crop parameter (LAI, DB, and height) estimation on wheat and rapeseed using optical or SAR parameters (Sec. 4.3).

\subsection{Synthetic Aperture Radar Angular Normalization}

The aim of this section was (1) to study the angular sensitivity of SAR parameters and (2) to correct the effects of the incidence angle on SAR signal according to their sensitivity. Different relationships were established between the angular sensitivity of radar backscattering coefficients or polarimetric indicators and NDVI values for rapeseed (10 points) and wheat fields (23 points) (e.g., Fig. 4).

The overall analysis of angular sensitivities is presented in Fig. 5, and discussed on the basis of the statistical performances ( $r^{2}$ and rRMSE) calculated for each $\Gamma$ function [Eq. (4)]. The coefficients of determination $\left(r^{2}\right)$ exhibit a wide range of values, linked to the nonangular 

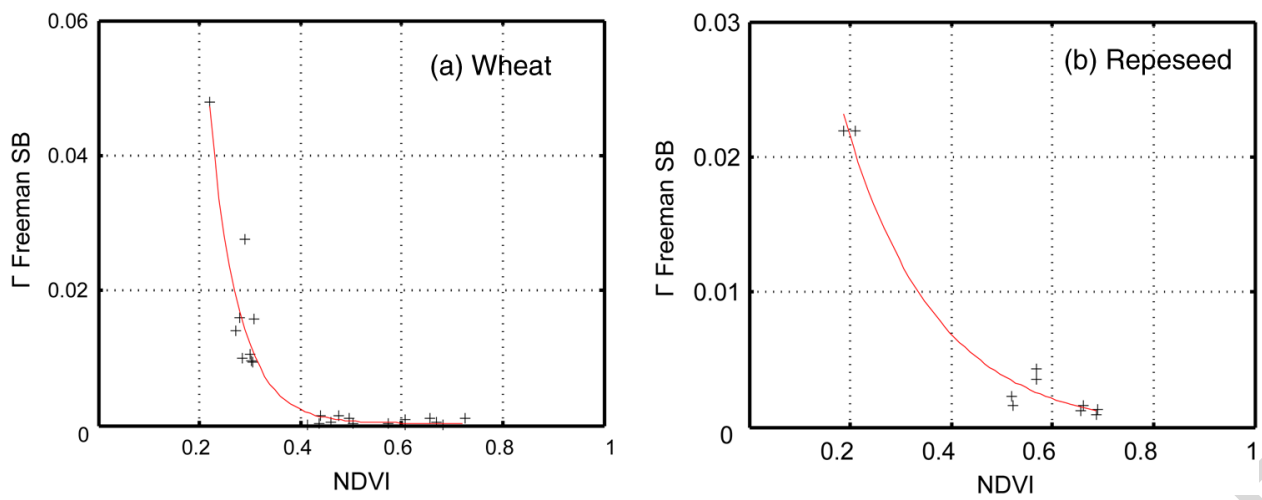

Fig. 4 Examples of relationships obtained between NDVI and the difference in Freeman SB between two successive images acquired at high and low incidence angles ( $\Gamma$ Freeman $S B$ ) for (a) wheat and (b) rapeseed.

sensitivity (e.g., in the case of the HH/VV ratio for both wheat and rapeseed) or to the strong angular sensitivity (e.g., for $\lambda_{1}$ and T11 over wheat fields, and $\sigma_{\mathrm{VV}}^{\circ}, \sigma_{\mathrm{HH}}^{\circ}$, and Freeman SB over rapeseed fields) of SAR parameters. The backscattering coefficients $\sigma_{\mathrm{HH}}^{\circ}$ and $\sigma_{\mathrm{VV}}^{\circ}$ and the polarimetric indicators related to the single-bounce scattering mechanism (i.e., $\lambda_{1}$, T11, and Freeman SB) are very sensitive to angular variations during the vegetation cycle $\left(0.7<r^{2}<0.98\right)$, decreasing exponentially as NDVI increases (Fig. 4), regardless of the considered crop. On the other hand, the backscattering coefficients $\sigma_{\mathrm{HV}}^{\circ}$ and the polarimetric indicators associated with double-bounce and volume scattering mechanisms (i.e., Freeman DB, Freeman VOL, $\lambda_{2}, \lambda_{3}, \mathrm{~T} 22$, and T33) present low coefficients of determination $\left(r^{2}<0.55\right)$. Moreover, the SAR parameters alpha, entropy, SEi, and SEp are more sensitive to angular variation on rapeseed fields than on wheat fields. Indeed, at the beginning of the vegetation cycle, these parameters are highly sensitive to angular variations since the vegetation does not fully cover the soil. This sensitivity decreases since the canopy becomes denser. This phenomenon is thus more pronounced for rapeseed fields, which shows a dense and complex canopy.

This study confirms the higher sensitivity of $\mathrm{HH}$ and $\mathrm{VV}$ polarizations to the incidence angle compared to HV polarization ${ }^{10,11,14,17}$ and extends results to polarimetric indicators. In the following sections, all SAR indicators are angular-normalized in accordance with Eqs. (4) and (5).

\subsection{Scattering Mechanism Analysis}

Scattering mechanisms of wheat and rapeseed fields are analyzed using polarimetric indicators that were the most sensitive to the crop phenological stages: polarimetric indicators derived from the Freeman-Durden and Cloude-Pottier decompositions, and the SE (which corresponds to the sum of SEi and SEp) (Figs. 6, 7, and 8). This analysis was part of a larger survey of polarimetric indicators that is not related here, for the sake of conciseness.
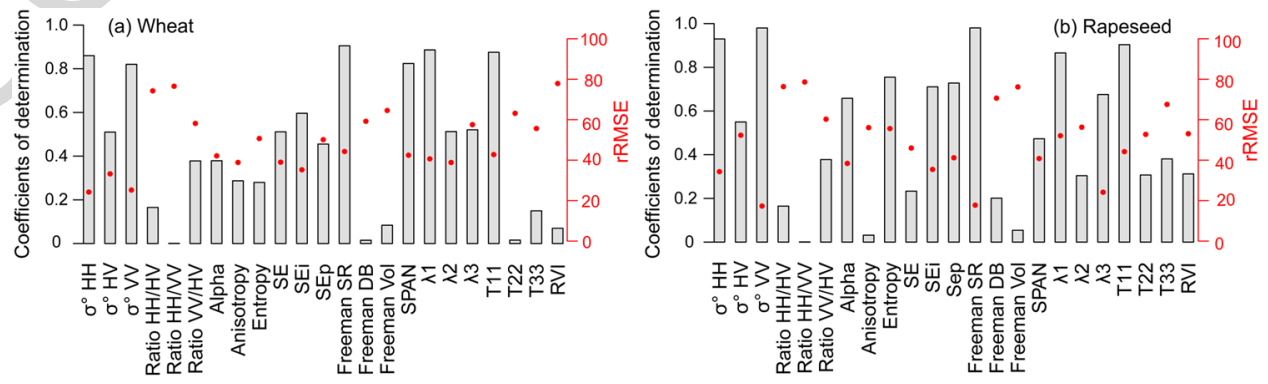

Fig. 5 Coefficients of determination and rRMSE of empirical relationships established between the NDVI values and the difference in backscattering coefficients or in polarimetric indicators between two successive images acquired at high and low incidence angles on (a) wheat and (b) rapeseed fields. 

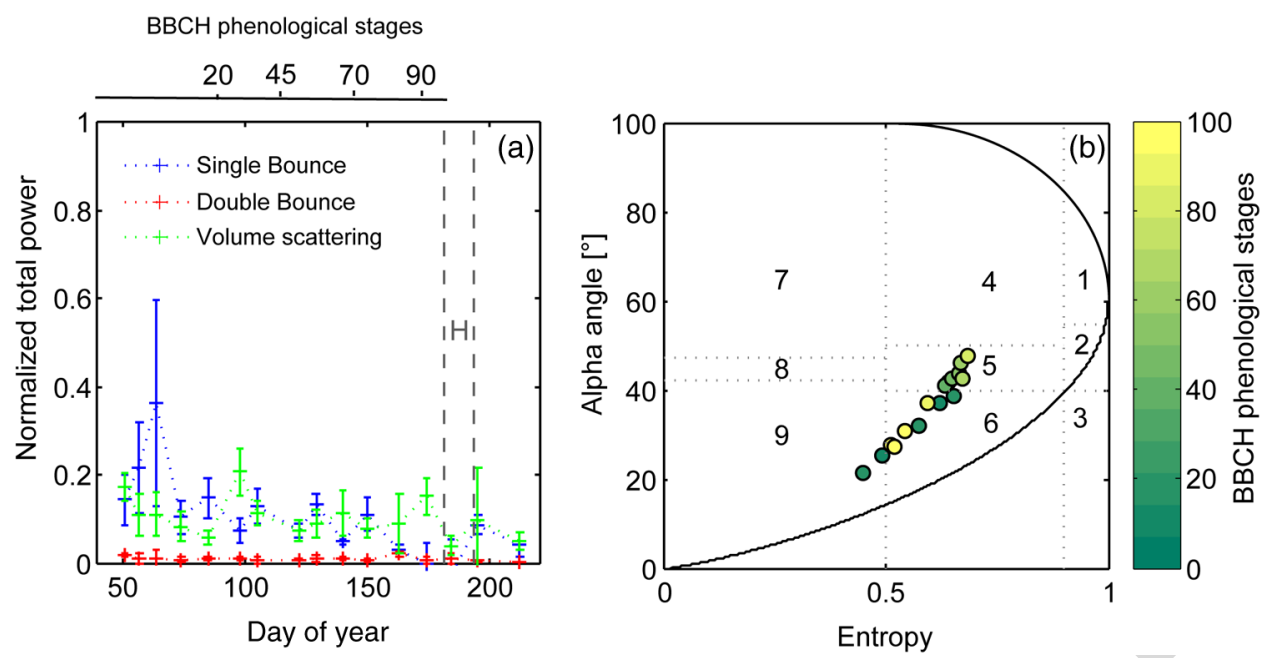

Fig. 6 (a) Wheat Freeman-Durden and (b) Cloude-Pottier ( $H-\alpha$ plan) decompositions derived from Radarsat-2 time series (mean value of the 14 instrumented fields for each acquisition date). The harvest period (DoY 181 to DoY 193) is also represented $(H)$.

Concerning wheat, results show that surface scattering dominates at the early stages of the crop development (peak of surface scattering [Fig. 6(a)] and dot in zone 9-5 of the $H-\alpha$ plan [Fig. 6(b)]), until the end of March [BBCH stage = 20-Tillering; day of year (DoY) 85]. At these stages, the crop height was around $15 \mathrm{~cm}$ and NDVI was close to 0.6. This behavior could be explained by the presence of bare soil between the crop rows, inducing a majority of soil contribution to the total backscattered signal. Cookmartin et al. ${ }^{53}$ confirm that at C-band, the scatter contributions are first dominated by the ground before being masked by leaves and stems. As vegetation grows, from mid-April (BBCH stage 25-Tillering; DoY 105) to the beginning of June (BBCH stage 70-Flowering, Anthesis; DoY 160; NDVI 0.8), the contributions of both single-bounce and volume scattering mechanisms are significant in almost the same proportion. On June 12, 2010 (DoY 163, BBCH stage 80-Ripening), the surface scattering decreases due to the presence of leaves and heads. On June 23, 2010 (DoY 174; BBCH stage 90—Ripening), a peak in volume scattering can be observed during the maturation phenological stage, due to an increase of biomass [Fig. 6(a)]. As illustrated in Fig. 6(b), the intensity of entropy increases with the $\alpha$ angle from DoY 105 to DoY 163 (inducing a shift of the dot in zone 5), which confirms the increase of volume scattering until its peak on DoY 174. At the same time, the NDVI decreases
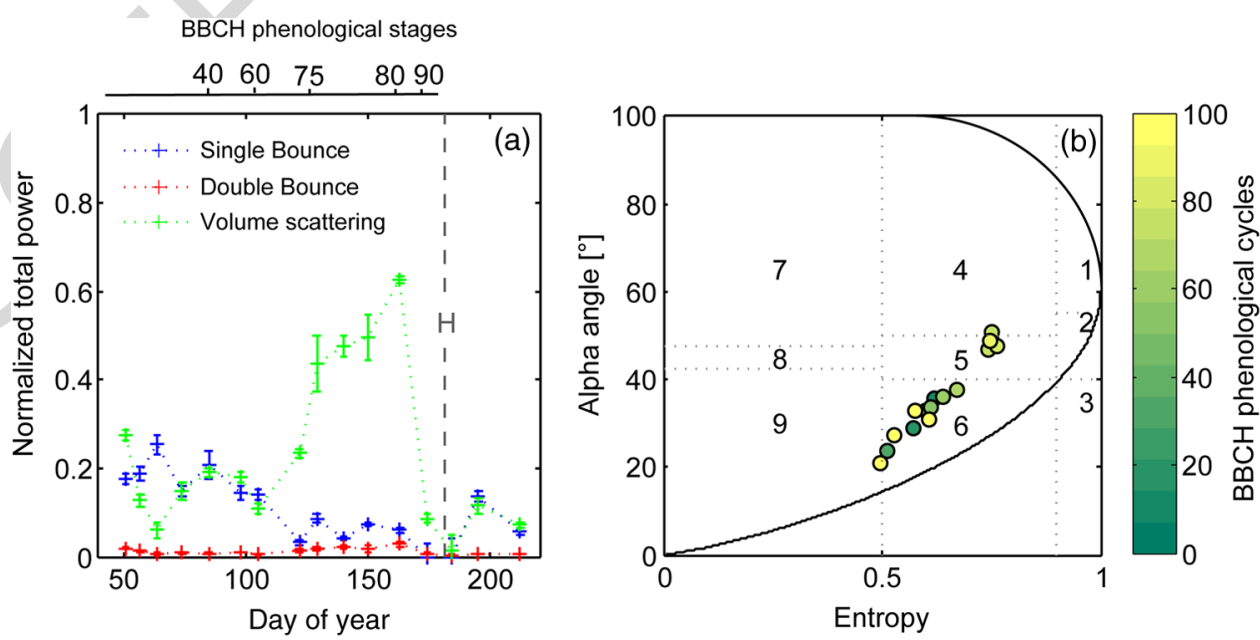

Fig. 7 (a) Rapeseed Freeman-Durden and (b) Cloude-Pottier ( $H-\alpha$ plan) decompositions derived from Radarsat-2 time series (mean value of the four rapeseed instrumented fields for each acquisition date). The day of harvest is also represented $(H)$. 

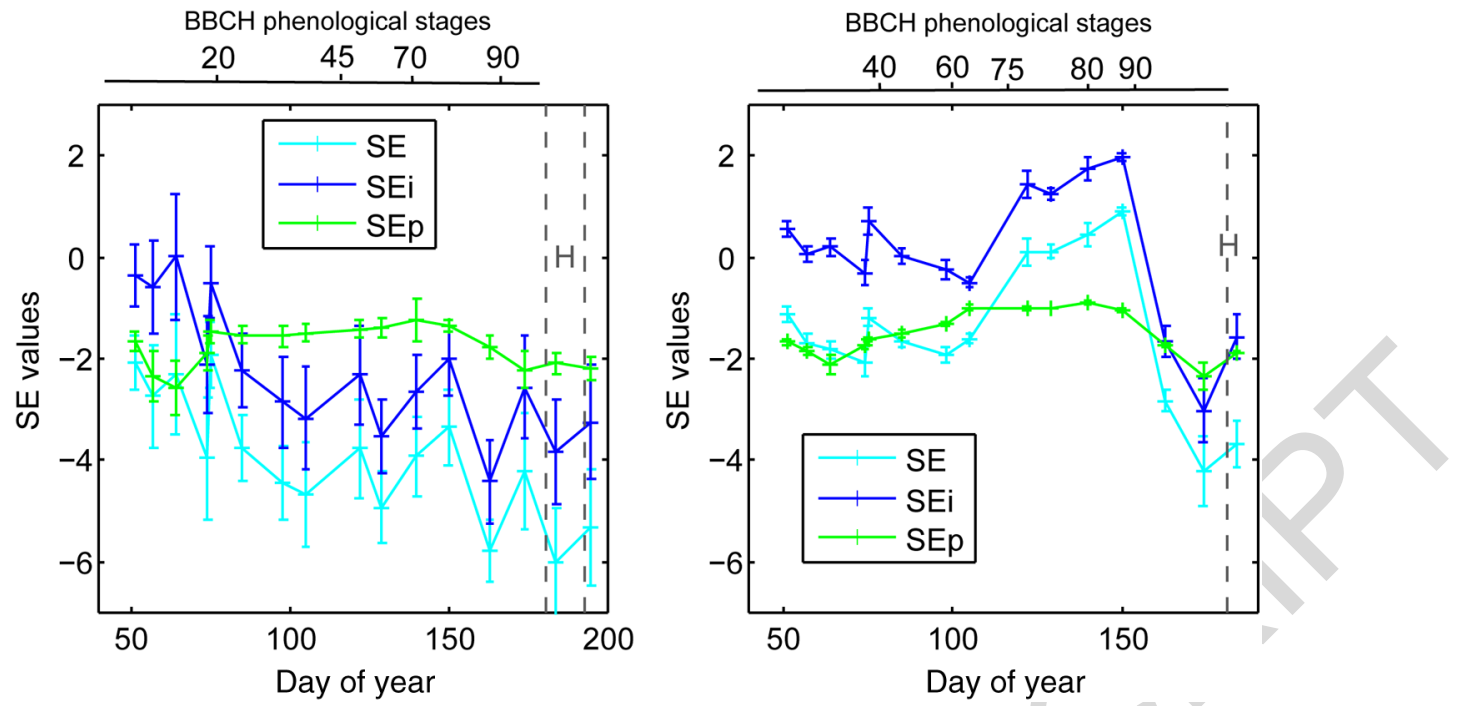

Fig. 8 SE, SEi, and SEp time profiles on (a) wheat and (b) rapeseed monitored fields during the entire vegetation cycle.

as the crop is drying and color-changing. These temporal behaviors can be associated with an increase in crop absorption when the vegetation is wet and a decrease when the vegetation is drying. ${ }^{53}$ These results are in agreement with the ones obtained by Cable et al., ${ }^{54}$ who observed an increase in volume scattering over wheat fields from June 20 to July 14 (BBCH stage 80Ripening) due to a rise in biomass. Then, during the senescence phenological stage (BBCH stage 100-Senescence), the volume scattering decreases [Fig. 6(a)] as DB decreases (Fig. 2). At this period, the dots are located in zone 6 (rough surface), confirming the decrease of volume scattering and the increase in surface scattering [Fig. 6(b)], as it was demonstrated by Cable et al. ${ }^{54}$ In contrast to optical data, ${ }^{17}$ the harvest period can thus be clearly identified using SAR data, by identifying a strong decrease of volume scattering.

High standard deviations can be observed for the three temporal profiles derived from the Freeman-Durden decomposition throughout the vegetation cycle, more particularly on singlebounce profiles at the beginning of the wheat vegetation cycles. Indeed, the differences in soil properties (i.e., from medium to fine according to the HYPRES textural triangle) over the 14 fields induced single-bounce values variability at this period of the vegetation season. As the crop is growing, the soil contribution to the total SAR signal decreases, inducing a decrease of the single-bounce signals variability between fields.

Concerning rapeseed, results show that surface scattering dominates at the early stages of the crop development, until the end of March (BBCH stage 45-Stem elongation; DoY 85). This could be explained by the presence of bare soil between the crop rows at these first phenological stages, inducing soil contribution to the total backscattered signal. At these stages, the crop height was $\sim 65 \mathrm{~cm}$ and the NDVI was close to 0.7 .

An increase in volume scattering is observed on April 8, 2010, when the crop starts to flower (DoY 98; BBCH stage 60-Inflorescence emergence). Since May 2, 2010 (DoY 122, BBCH stage 70-Flowering), single-bounce scattering mechanisms decrease, leading to volume scattering as the principal scattering mechanism. After flowering, the geometry of the rapeseed canopy becomes more complex (with randomly oriented canopy components), due to fruit development and fall of leaves, inducing a strong increase in the contribution of volume scattering [ $\Delta$ VOL $\sim 0.5$, Fig. 7(a)] until a peak on June 12, 2010 (DoY 163, BBCH stage 80-Ripening). This phenomenon is also observed following the Cloude-Pottier decomposition, with a shift of the dot from zone 6 to zone 5 [Fig. 7(b)]. This peak can be explained by the presence of mature pods at the end of the ripening phenological stage. ${ }^{17,54,55}$ On DoY 170 (BBCH stage 90Senescence), the volume scattering mechanism decreases [dot in zone 6 regarding the Cloude-Pottier decomposition, Fig. 7(b)] since the vegetation reaches the senescence phenological stage. This decrease can be explained by a strong decline of the water content of the top 
vegetation layer (from 60 to $30 \%{ }^{39}$ ), inducing higher wave penetration into the soil and thus a decrease of the volume scattering. ${ }^{55}$ It is interesting to notice that this decrease cannot be perceived on the backscattering coefficient $\sigma_{\mathrm{HV}}^{\circ}$ temporal profiles, ${ }^{17}$ showing that volume scattering is more sensitive to the plant water content than $\sigma_{\mathrm{HV}}^{\circ}$. Moreover, from DoY 98 to DoY 184, radar signal is not affected by the TSM. Again, the harvest is clearly identifiable by a decrease of volume scattering [Fig. 7(b)], which is not possible using optical vegetation indexes. ${ }^{17}$

Temporal dynamics of SE, SEi, and SEp on rapeseed and wheat fields are for the first time in our knowledge analyzed using multitemporal and multiangular SAR data (Fig. 8). The SE measures the randomness of scattering of a pixel, which can be due to the variation of backscattering power SEi or the variation of the backscattering polarization SEp. The high dynamic observed on $\mathrm{SE}$, regardless of the considered crop, is mainly due to SEi variations ( $\Delta \mathrm{SE}$ and $\Delta \mathrm{SEi} \sim 3$ ), the two profiles being strongly correlated.

Concerning fields of wheat [Fig. 8(a)], SEp first decreases from DoY 51 to DoY 64 (BBCH stage 10-Leaf development) and then increases to reach signal saturation on DoY 85 (BBCH stage 20-End of leaf development). This variation of backscattering polarization is quite low $(\Delta \mathrm{SEp} \sim 1.5)$ and seems to be mainly induced by the development of the leaves and stems (first BBCH stages). The highest dynamics are observed on the SE and SEi temporal profiles. At the beginning of the phenological stages [from February (DoY 51) to mid-April (DoY 104)], SEi fluctuations are mainly related to TSM variations $\left(r^{2}=0.7\right)$ (Fig. 9). On DoY 130 and DoY 162, the little inflection of SEi signals can be attributed to important rain events (increasing the TSM and the free water at the surface of the crop), as it was demonstrated by Fieuzal et al. ${ }^{17}$ on backscattering coefficients temporal profiles. During the senescence phenological stage, SEi decreases, since the water content of the crop decreases inducing higher wave penetration into the soil.

Concerning fields of rapeseed [Fig. 8(b)], SEi and SEp are not sensitive to the same rapeseed phenological stages. SEi shows its highest dynamic during the filling pods phenological stages and SEp during the first phenological stages. SEp regularly increases from DoY 64 (BBCH stage 30-Formation of side shoots) to crop flowering (DoY 105) and then saturates until the pod maturation (DoY 163). During this first period, the architecture of the plant changed (from a thick rosette of leaves to a flowering stalk), inducing high variation of backscattering polarization, and thus an increase in SEp values. It can also be noticed that all rapeseed fields show the same profile behavior since the standard deviation is very low throughout the vegetation cycle (mainly explained by the similar soil textural properties on the four instrumented fields). SEi is mainly affected from the flowering (DoY 98; BBCH stage 60 , DB $\sim 1000 \mathrm{~g} \cdot \mathrm{m}^{-2}$ ) to the pods maturation (DoY 163, BBCH stage 90, DB $\sim 2200 \mathrm{~g} \cdot \mathrm{m}^{-2}$ ). During this period, the total biomass of the crop becomes higher and the canopy more complex (randomly oriented components), inducing an increase of the backscattered power, due to the increase of volume scattering as demonstrated by Cloude-Pottier and Freeman-Durden decompositions. In comparison to optical data, SEp shows its highest dynamic during the first phenological stages, as NDVI temporal profile. ${ }^{17} \mathrm{SEi}$ is more sensitive to the filling pods phenological stages, which are not identifiable by optical data, demonstrating the complementarity of SAR data.

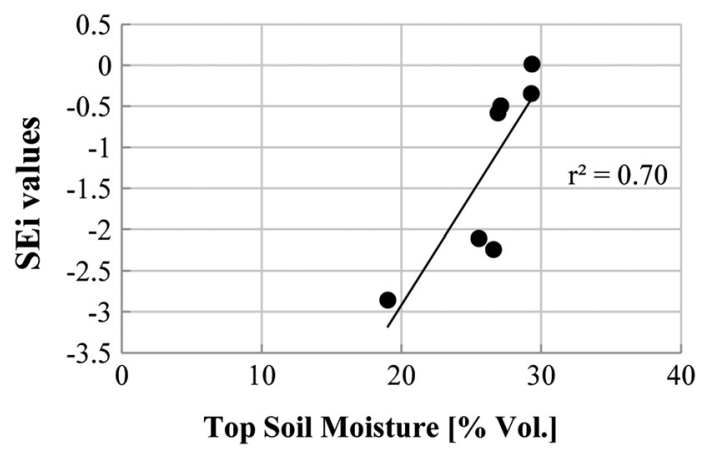

Fig. 9 Relationships established between SEi (from DoY 51 to DoY 104) and TSM (\%. vol.) (mean value of the 14 instrumented fields for each acquisition date). 


\subsection{Optical and Synthetic Aperture Radar Angular-Normalized Signals Sensitivity to Crop Parameters}

Performances of exponential empirical relationships established between optical or SAR angular-normalized signals and LAI, vegetation heights, or DB [Eq. (1)] are summarized in Figs. 10 and 11. The results show that SAR indicators are more suitable than optical parameter (i.e., NDVI) for crop parameters estimation for the two studied crops.

Concerning wheat, significant nonlinear regressions can be observed between the wheat height, LAI, or DB measured all along the vegetation cycle and some backscattering coefficients or polarimetric indicators derived from the Radarsat-2 time series (Fig. 10). The best results [Table 4 and Fig. 12(a)] are obtained (1) from $\sigma_{\mathrm{VV}}^{\circ}$ and alpha angle for monitoring height $\left(r^{2}=0.60\right.$ and 0.57 , respectively), (2) from the ratio $\mathrm{HH} / \mathrm{HV}$ for monitoring LAI $\left(r^{2}=0.53\right)$, and (3) from $\sigma_{\mathrm{VV}}^{\circ}$ for monitoring $\mathrm{DB}\left(r^{2}=0.69\right)$. It is interesting to notice that the SAR signal shows saturation for a wheat height of $60 \mathrm{~cm}$ and DB of $250 \mathrm{~g} \cdot \mathrm{m}^{-2}$ $(\mathrm{BBCH}$ phenological cycle $=50)$ [Fig. 12(a), Table 4]. For this crop, the contribution of polarimetric indicators is poor, and the use of backscattering coefficients significantly increases the variance explained of the statistical models $(+40 \%$ for vegetation height and $+20 \%$ for DB).

In comparison, Fieuzal et al. ${ }^{17}$ showed strong correlations between $\sigma_{\mathrm{VV}}^{\circ}$ and wheat height $\left(r^{2}=0.61\right)$ until signal saturation reached at $65 \mathrm{~cm}$, which is in accordance with our results. Moreover, they demonstrated a higher potential of $\sigma_{\mathrm{VV}}^{\circ}$ for wheat LAI estimation than of $\sigma_{\mathrm{HH}}^{\circ}$ and $\sigma_{\mathrm{HV}}^{\circ}\left(r^{2}=0.58, r^{2}=0.33\right.$, and $r^{2}=0.21$, respectively). Our results further confirmed these results regarding co- and cross-polarization signals behavior (Fig. 10). Other studies ${ }^{12,30}$ demonstrated the potential of $\sigma_{\mathrm{VV}}^{\circ}$ for wheat DB estimation at $23 \mathrm{deg}$ incidence angle (at least before heading, modulated by changes in soil moisture) and of the ratio $\mathrm{HH} / \mathrm{VV}$ at 43 deg incidence angle (during the growing season). In this study, we showed that $\sigma_{\mathrm{VV}}^{\circ}$ corresponds to the best SAR indicators for wheat DB estimation until the inflorescence emergence (BBCH phenological stage $\sim 50$ and $\mathrm{DB}=250 \mathrm{~g} \cdot \mathrm{m}^{-2}$ ). This difference can mainly be explained by the number of fields monitored: 1 in the study conducted by Mattia et al. ${ }^{12}$ and 14 in our study (landscape approach), leading to a strong heterogeneity in surfaces conditions (e.g., soil moisture, roughness, texture, crop species, maturity).

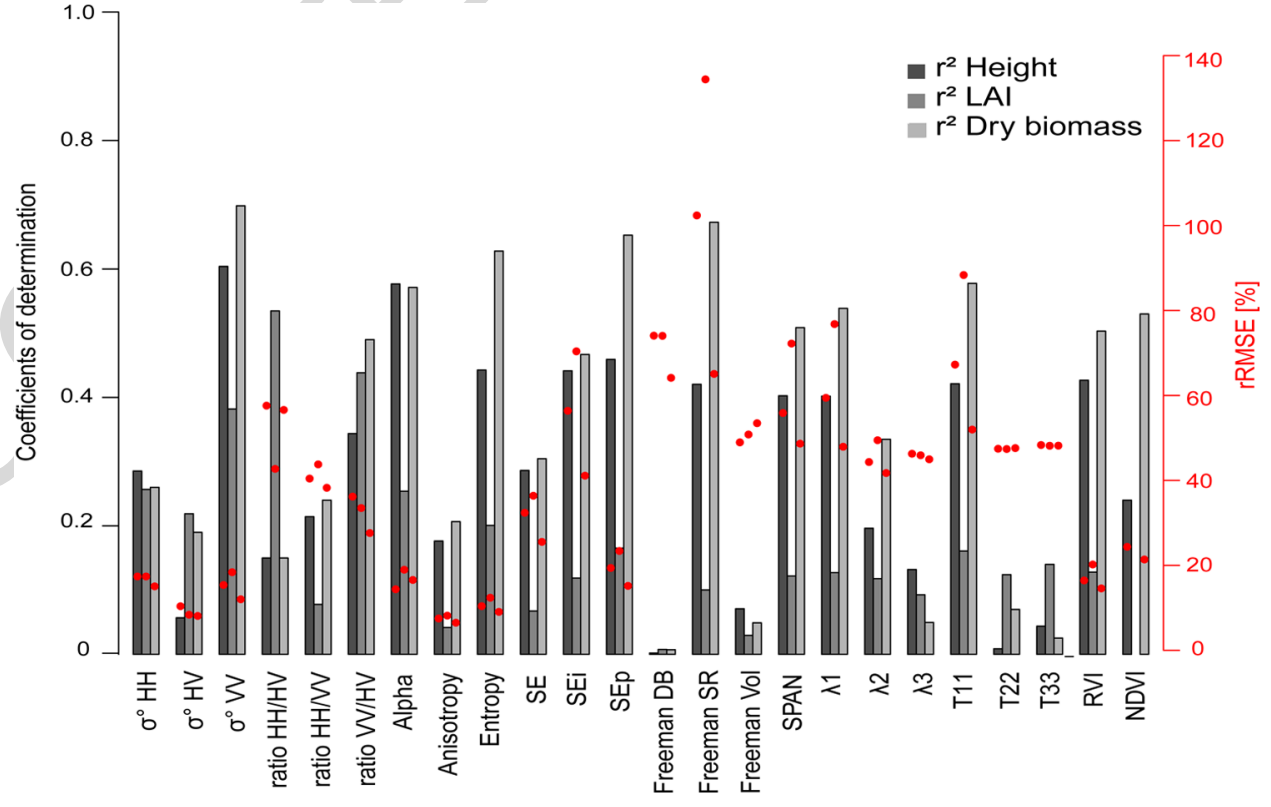

Fig. 10 Coefficients of determination and rRMSE of exponential empirical relationships established between the wheat height, LAI, and DB and satellite signals (backscattering coefficients, polarimetric indicators, and NDVI). 


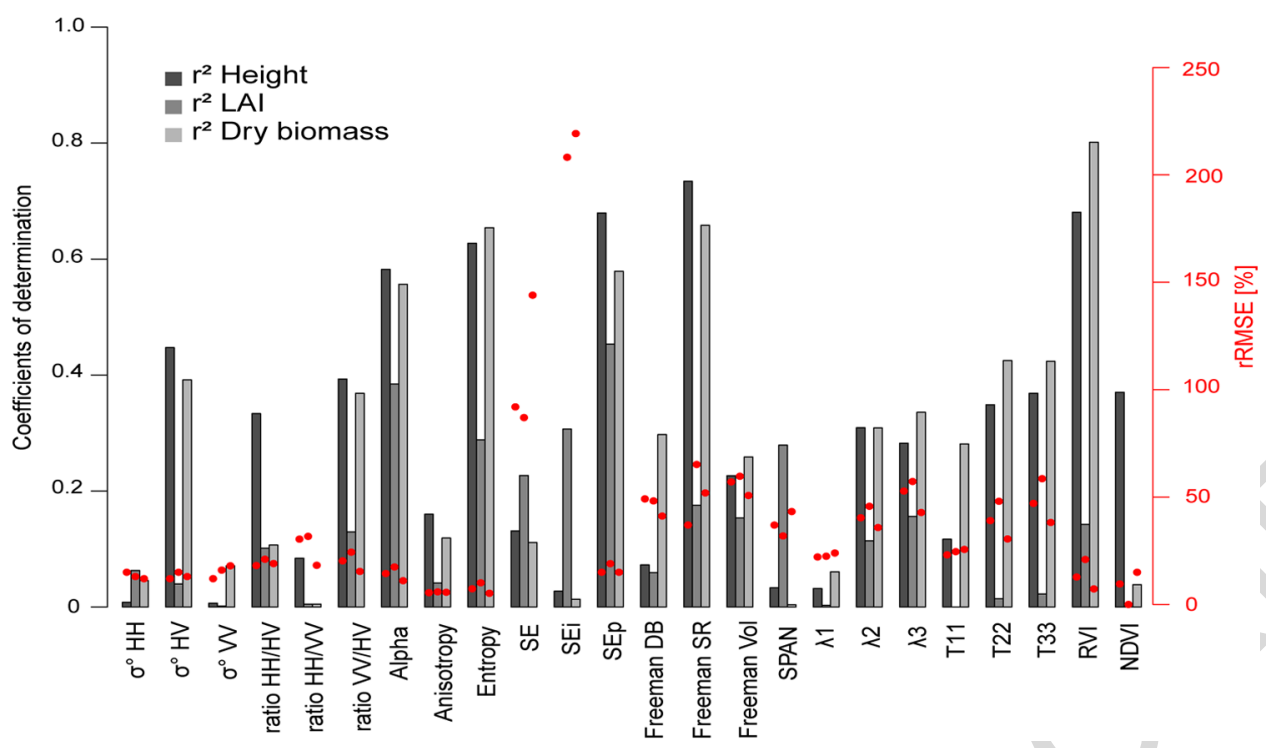

Fig. 11 Coefficients of determination and rRMSE of exponential empirical relationships established between the rapeseed height, LAI, and DB and satellite parameters (backscattering coefficients, polarimetric indicators, and NDVI).

Concerning polarimetric indicators, Wiseman et al. ${ }^{19}$ found that the best PolSAR parameters for wheat DB estimations in a linear way corresponds to the circular polarization ratio LR/LL $\left(r^{2}=0.44\right)$. They also showed that some polarimetric indicators (i.e., volume scattering and pedestrial height) were capable of detecting when wheat entered the milking stage, which could be a good indicator for the timing of wheat harvest. Jin et al. ${ }^{29}$ demonstrated the high performances of RVI and double-bounce eigenvalue relative difference time series for wheat DB and LAI estimations ( $r^{2}=0.65$ and $r^{2}=0.8$, respectively). Because of the different approaches adopted, the results cannot be compared directly. Indeed, Wiseman et al. ${ }^{19}$ did not take into account the VV backscattering coefficients and considered only a part of the vegetation cycle, contrary to this work. Spring wheat was already matured (entering the milking

Table 4 Parameter values ( $a, b$, and $c$ ) of the best exponential relationships established between the height, LAl, and DB of wheat and rapeseed and satellite parameters (backscattering coefficients and polarimetric indicators). Their corresponding statistics for determination coefficient, absolute and relative root mean square error $\left(r^{2}, \mathrm{RMSE}\right.$, and $\mathrm{rRMSE}$, respectively) are also given. Moreover, when the SAR or optical signal saturates, the values of crop parameters and $\mathrm{BBCH}$ phenological stage are specified.

\begin{tabular}{lccccccccc}
\hline \hline & $\begin{array}{c}\text { Remote } \\
\text { sensing } \\
\text { indicators }\end{array}$ & $a$ & $b$ & $c$ & $r^{2}$ & RMSE & $\begin{array}{c}\text { rRMSE } \\
(\%)\end{array}$ & $\begin{array}{c}\text { BBCH } \\
\text { phonological } \\
\text { stage saturation }\end{array}$ & $\begin{array}{c}\mathrm{CP} \\
\text { saturation }\end{array}$ \\
\hline Wheat & & & & & & & & & \\
Height & $\sigma_{\mathrm{VV}}^{\circ}$ & 8.6 & -0.03 & -14.87 & 0.60 & 1.8 & 15 & 50 & $60 \mathrm{~cm}$ \\
LAl & $\sigma_{\mathrm{HH}}^{\circ} / \sigma_{\mathrm{HV}}^{\circ}$ & 2320 & -0.002 & -2292 & 0.53 & 5.7 & 41 & - & - \\
DB & $\sigma_{\mathrm{VV}}^{\circ}$ & 8.69 & -0.01 & -13.9 & 0.69 & 1.46 & 11 & 50 & $250 \mathrm{~g} \mathrm{~m}^{-2}$ \\
Rapeseed & & & & & & & & & - \\
Height & $\mathrm{SEp}$ & -16.6 & -0.02 & 14.2 & 0.67 & 0.21 & 15 & - & - \\
LAl & $\mathrm{SEp}$ & -10.61 & -2.23 & 11.2 & 0.45 & 0.28 & 19 & 70 & $3.5 \mathrm{~m}^{2} \mathrm{~m}^{-2}$ \\
DB & $\mathrm{RVI}$ & -8.99 & -0.0005 & 7.04 & 0.80 & 0.07 & 7 & - & - \\
\hline \hline
\end{tabular}


stage and stem elongation) at the beginning of their field acquisition campaign. Jin et al. ${ }^{29}$ studied only a part of the vegetation cycle using four RADARSAT-2 images (from tillering to filling).

Concerning the estimation of rapeseed parameters, this study demonstrated the high potential of polarimetric indicators. Indeed, correlations between the height, LAI, or DB measured all along the vegetation cycle and polarimetric indicators are always higher than the ones established with backscattering coefficients or NDVI (Fig. 11). Again, radar indicators significantly increased the variance explained by the statistical models in comparison to optical parameter ( $+30 \%$ for rapeseed height and $+75 \%$ for rapeseed DB). The best results (Table 4$)$ are obtained from (1) SEp and Freeman SB for monitoring height $\left(r^{2} \sim 0.7\right)$, (2) SEp for monitoring LAI $\left(r^{2}=0.45\right)$, and (3) RVI for monitoring DB $\left(r^{2}=0.80\right)$. A signal saturation of SEp can be observed for a BBCH phenological stage of 70 (when LAI reached $3.5 \mathrm{~m}^{2} \cdot \mathrm{m}^{-2}$ ) [Fig. 12(b)]. Polarimetric parameters SEp and RVI demonstrated their potential to estimate in a linear way rapeseed height and DB all along the vegetation cycle [Fig. 12(b)]. Fieuzal et al. ${ }^{17}$ shows a high sensitivity of the ratio $\mathrm{HH} / \mathrm{HV}$ to LAI of rapeseed $\left(r^{2}=0.66\right.$ for an LAI maximum of $\left.3.83 \mathrm{~m}^{2} \cdot \mathrm{m}^{-2}\right)$ and to rapeseed height $\left(r^{2}=0.73\right.$ for a height maximum of $200 \mathrm{~cm}$, without the senescence phenological stage). Results presented here demonstrate that unlike backscattering coefficients (where relationships are restricted to the first phenological stages), polarimetric indicators allow estimating LAI and DB during the whole vegetation cycle. Better results were found in this study for DB estimations in comparison to Wiseman et al. ${ }^{19}$ (using $\mathrm{HV}$ or volume scattering mechanisms $\left(r^{2} \sim 0.75\right)$ without taking into account the flowering phenological stages).
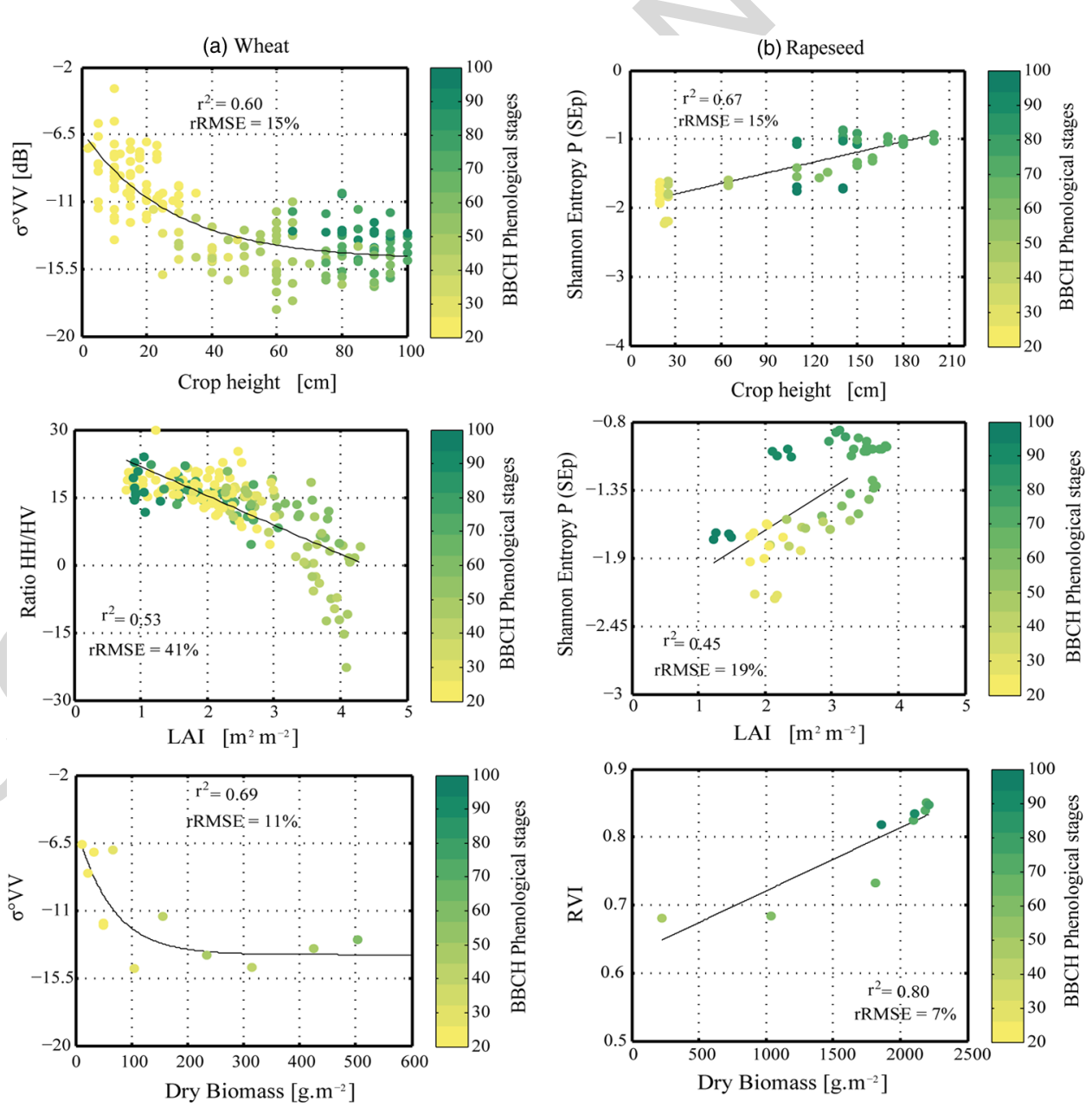

Fig. 12 Best relationships obtained between (a) wheat and (b) rapeseed height, LAI or DB and backscattering coefficients or polarimetric parameters. 


\section{Conclusion}

This paper aimed to evaluate the contribution of polarimetric SAR indicator compared to backscattering coefficient and to optical vegetation index (NDVI) for rapeseed and wheat monitoring. Three dependent sections have been developed.

First, the results showed the importance of correcting the angular effect on SAR signals especially for copolarized signals and polarimetric indicators reflecting single-bounce scattering mechanisms. They also revealed that cross-polarized signals (i.e., HV) and polarimetric indicators linked with double-bounce or volume scattering mechanism (i.e., Freeman volume, Freeman DB, T22, T33) were insensitive to incidence angle variations; thus, angular correction was not as critical for those indicators.

Second, the study has made a significant contribution to the analysis of polarimetric data responses (including Freeman-Durden and Cloude-Pottier decomposition, SE) to rapeseed and wheat crop development (growth stages) during the entire vegetation cycle (thanks to a dense satellite temporal sampling from first phenological stages to harvest). The analysis of the temporal dynamic of polarimetric indicators has shown their high potential to detect crop growth changes. Surface scattering dominates at the early stages of the crop development followed by an increase in volume scattering during the crop maturation over wheat fields and after flowering over rapeseed fields (according to the Freeman-Durden and Cloude-Pottier decompositions). As expected, higher backscatter values and volume scattering mechanisms were observed on rapeseed fields than on wheat fields, due to the more complex and dense rapeseed canopy. The analysis of SEi and SEp temporal profiles showed their interest since they are not sensitive to the same phenological stages particularly over rapeseed fields. SEi shows its highest dynamic during the filling pods phenological stages and SEp during the first phenological stages. Moreover, the harvest is clearly identifiable for these two crops, by a strong decrease of volume scattering, which is not possible using optical images.

Finally, this study has shown the high interest of using SAR parameters (backscattering coefficients and polarimetric indicators) for crop parameters estimation during the whole vegetation cycle instead of using optical vegetation index (results based on $r^{2}$ and rRMSE values). Although polarimetric indicators did not improve wheat parameters, backscattering coefficients acquired in VV polarization show their interest for wheat height and DB estimations in comparison to optical data $(+40 \%$ of variance explained for vegetation height modeling and $+20 \%$ for DB modeling). Concerning rapeseed, polarimetric indicators have shown their high potential for crop height and DB monitoring (i.e., SEp; $r^{2}=0.67$ and RVI; $r^{2}=0.80$, respectively, and rRMSE $<15 \%$ ) instead of using backscattering coefficients or optical vegetation index. Results also demonstrated that contrary to backscattering coefficients (where relationships are restricted to the first phenological stages), the use of polarimetric signal allows estimating the LAI and DB during the whole vegetation cycle.

In the perspective of this study, it would be interesting to extend this approach to another crop type (corn, sunflower, and so on) and investigate polarimetric indicators derived from other SAR configurations (X-and L-band) for wheat and rapeseed monitoring. Finally, this study opened interesting perspectives for crop yield estimation at a fine scale, using the assimilation of SAR (polarimetric and backscatter) data acquired by sensors with high repetitiveness (e.g., Sentinel-1) into agrometeorological models.

\section{Acknowledgments}

This work was supported by the CNES-TOSCA program (postdoctorate grant to J. Betbeder). The authors would like to thank Space Agencies (CNES, ESA, CSA) and SOAR Project (Project No. 6843) for their support, funding, and for providing satellite imagery. The authors are also grateful to the farmers and the people who helped collect ground data.

\section{References}

1. C. Atzberger, "Advances in remote sensing of agriculture: context description, existing operational monitoring systems and major information needs," Remote Sens. 5, 949-981 (2013). 
Betbeder et al.: Contribution of multitemporal polarimetric synthetic aperture radar...

2. B. Grieve et al., "Localized multispectral crop imaging sensors: engineering \& validation of a cost effective plant stress and disease sensor," in 2015 IEEE Sensors Applications Symp., pp. 1-6 (2015).

3. B. Duchemin et al., "Impact of sowing date on yield and water use efficiency of wheat analyzed through spatial modeling and FORMOSAT-2 images," Remote Sens. 7, 59515979 (2015).

4. D. J. Mulla, "Twenty five years of remote sensing in precision agriculture: key advances and remaining knowledge gaps," Biosyst. Eng. 114, 358-371 (2013).

5. J. Betbeder, R. Fieuzal, and F. Baup, "Assimilation of LAI and dry biomass data from optical and SAR images into an agro-meteorological model to estimate soybean yield," IEEE J. Sel. Top. Appl. Earth Obs. Remote Sens. (in press).

6. M. Claverie et al., "Maize and sunflower biomass estimation in southwest France using high spatial and temporal resolution remote sensing data," Remote Sens. Environ. 124, 844-857 (2012).

7. B. Duchemin et al., "A simple algorithm for yield estimates: evaluation for semi-arid irrigated winter wheat monitored with green leaf area index," Environ. Model. Softw. 23, 876-892 (2008).

8. J. Liu, E. Pattey, and G. Jégo, "Assessment of vegetation indices for regional crop green LAI estimation from Landsat images over multiple growing seasons," Remote Sens. Environ. 123, 347-358 (2012).

9. D. Haboudane et al., "Hyperspectral vegetation indices and novel algorithms for predicting green LAI of crop canopies: modeling and validation in the context of precision agriculture," Remote Sens. Environ. 90, 337-352 (2004).

10. F. T. Ulaby, R. K. Moore, and A. K. Fung, Microwave Remote Sensing, Vol. 3, Artech House Publishers, Norwood, Massachusetts (1986).

11. H. Skriver, M. T. Svendsen, and A. G. Thomsen, "Multitemporal C- and L-band polarimetric signatures of crops," IEEE Trans. Geosci. Remote Sens. 37, 2413-2429 (1999).

12. F. Mattia et al., "Multitemporal C-band radar measurements on wheat fields," IEEE Trans. Geosci. Remote Sens. 41, 1551-1560 (2003).

13. H. McNairn and B. Brisco, "The application of C-band polarimetric SAR for agriculture: a review," Can. J. Remote Sens. 30, 525-542 (2004).

14. A. Balenzano et al., "Dense temporal series of C- and L-band SAR data for soil moisture retrieval over agricultural crops," IEEE J. Sel. Top. Appl. Earth Obs. Remote Sens. 4, 439450 (2011).

15. M. Aubert et al., "Analysis of TerraSAR-X data sensitivity to bare soil moisture, roughness, composition and soil crust," Remote Sens. Environ. 115, 1801-1810 (2011).

16. F. Wu et al., "Rice crop monitoring in south china with RADARSAT-2 quad-polarization SAR data," IEEE Geosci. Remote Sens. Lett. 8, 196-200 (2011).

17. R. Fieuzal, F. Baup, and C. Marais-Sicre, "Monitoring wheat and rapeseed by using synchronous optical and radar satellite data-from temporal signatures to crop parameters estimation," Adv. Remote Sens. 2, 162-180 (2013).

18. C. Liu et al., "Multiyear crop monitoring using polarimetric RADARSAT-2 data," IEEE Trans. Geosci. Remote Sens. 51, 2227-2240 (2013).

19. G. Wiseman et al., "RADARSAT-2 polarimetric SAR response to crop biomass for agricultural production monitoring," IEEE J. Sel. Top. Appl. Earth Obs. Remote Sens. 7, 4461-4471 (2014).

20. S. Paloscia et al., "The potential of C- and L-band SAR in estimating vegetation biomass: the ERS-1 and JERS-1 experiments," IEEE Trans. Geosci. Remote Sens. 37, 2107-2110 (1999).

21. N. Baghdadi et al., "Potential of SAR sensors TerraSAR-X, ASAR/ENVISAT and PALSAR/ALOS for monitoring sugarcane crops on Reunion Island," Remote Sens. Environ. 113, 1724-1738 (2009).

22. G. Fontanelli et al., "Sensitivity analysis of X-band SAR to wheat and barley leaf area index in the Merguellil Basin," Remote Sens. Lett. 4, 1107-1116 (2013).

23. J. M. Lopez-Sanchez, I. Hajnsek, and J. D. Ballester-Berman, "First demonstration of agriculture height retrieval with PolInSAR airborne data," IEEE Geosci. Remote Sens. Lett. 9, 242-246 (2012). 
24. J.-S. Lee and E. Pottier, Polarimetric Radar Imaging: From Basics to Applications, CRC Press, Boca Raton, Florida (2009).

25. X. Jiao et al., "The sensitivity of RADARSAT-2 polarimetric SAR data to corn and soybean leaf area index," Can. J. Remote Sens. 37, 69-81 (2011).

26. Y. Kim et al., "Radar vegetation index for estimating the vegetation water content of rice and soybean," IEEE Geosci. Remote Sens. Lett. 9, 564-568 (2012).

27. S. Gao et al., "Estimating the leaf area index, height and biomass of maize using HJ-1 and RADARSAT-2," Int. J. Appl. Earth Obs. Geoinf. 24, 1-8 (2013).

28. M. Hosseini et al., "Estimation of leaf area index (LAI) in corn and soybeans using multipolarization C- and L-band radar data," Remote Sens. Environ. 170, 77-89 (2015).

29. X. Jin et al., "Combined multi-temporal optical and radar parameters for estimating LAI and biomass in winter wheat using HJ and RADARSAR-2 data," Remote Sens. 7, 13251-13272 (2015).

30. L. Dente et al., "Assimilation of leaf area index derived from ASAR and MERIS data into CERES-Wheat model to map wheat yield," Remote Sens. Environ. 112, 1395-1407 (2008).

31. R. Fieuzal and F. Baup, "Estimation of sunflower yield using multi-spectral satellite data (optical or radar) in a simplified agro-meteorological model," in 2015 IEEE Int. Geoscience and Remote Sensing Symp., pp. 4001-4004, IEEE (2015).

32. F. Baup, R. Fieuzal, and J. Betbeder, "Estimation of soybean yield from assimilated optical and radar data into a simplified agrometeorological model," in 2015 IEEE Int. Geoscience and Remote Sensing Symp., pp. 3961-3964 (2015).

33. S. Moulin, A. Bondeau, and R. Delecolle, "Combining agricultural crop models and satellite observations: from field to regional scales," Int. J. Remote Sens. 19, 1021-1036 (1998).

34. M. Guérif and C. L. Duke, "Adjustment procedures of a crop model to the site specific characteristics of soil and crop using remote sensing data assimilation," Agric. Ecosyst. Environ. 81, 57-69 (2000).

35. D. B. Lobell et al., "Remote sensing of regional crop production in the Yaqui Valley, Mexico: estimates and uncertainties," Agric. Ecosyst. Environ. 94, 205-220 (2003).

36. A. Olioso et al., "Future directions for advanced evapotranspiration modeling: assimilation of remote sensing data into crop simulation models and SVAT models," Irrig. Drain. Syst. 19, 377-412 (2005).

37. L'Observatoire Midi-Pyrénées, Observatoire Spatial Régional (OSR), http://www.obs-mip. fr/services-observation/soa/OSR (2013).

38. C. Marais Sicre, F. Baup, and R. Fieuzal, "Determination of the crop row orientations from Formosat-2 multi-temporal and panchromatic images," ISPRS J. Photogramm. Remote Sens. 94, 127-142 (2014).

39. F. Baup et al., "MCM'10: an experiment for satellite multi-sensors crop monitoring from high to low resolution observations," in 2012 IEEE Int. Geoscience and Remote Sensing Symp., pp. 4849-4852 (2012).

40. H. Bleiholder et al., "Growth stages of mono-and dicotyledonous plants, BBCH monograph," Federal Biological Research Centre for Agriculture and Forestry, Berlin/Braunschweig, Germany, p. 158 (2001).

41. European Soil Bureau Working Group, "Hydraulic properties of European soils (HYPRES)," Texture Classes. HYPRES Website, http://www.macaulay.ac.uk/hypres/ hypressoil.html (1997).

42. A. Sand and H. De Boissezon, "Reference remote sensing data bases: temporal series of calibrated and ortho-rectified satellite images for scientific use," in 2nd Int. Symp. on Recent Advances in Quantitative Remote Sensing (2006).

43. O. Hagolle et al., "A multi-temporal method for cloud detection, applied to FORMOSAT-2, VEN $\mu$ S, LANDSAT and SENTINEL-2 images," Remote Sens. Environ. 114, 1747-1755 (2010).

44. J. Liu et al., "Quantifying crop biomass accumulation using multi-temporal optical remote sensing observations," in 30th Canadian Symp. on Remote Sensing (2009).

45. H. McNairn et al., "Establishing crop productivity using RADARSAT-2," Int. Arch. Photogramm. Remote Sens. Spat. Inf. Sci. 39, B8 (2012). 
46. V. Demarez et al., "Estimation of leaf area and clumping indexes of crops with hemispherical photographs," Agric. For. Meteorol. 148, 644-655 (2008).

47. P. Dusseux et al., "Combined use of multi-temporal optical and radar satellite images for grassland monitoring," Remote Sens. 6, 6163-6182 (2014).

48. W. Li et al., "A generic algorithm to estimate LAI, FAPAR and FCOVER variables from SPOT4_HRVIR and landsat sensors: evaluation of the consistency and comparison with ground measurements," Remote Sens. 7, 15494-15516 (2015).

49. RADARSAT International, "RADARSAT Data Product Specification," Technical Report, Doc. No. RSI-GS-026, Rev. 3/0, p. 133, (2000).

50. E. Pottier and L. Ferro-Famil, "PolSARPro V5.0: an ESA educational toolbox used for selfeducation in the field of POLSAR and POL-INSAR data analysis," in 2012 IEEE Int. Geoscience and Remote Sensing Symp., pp. 7377-7380 (2012).

51. S. R. Cloude and E. Pottier, "An entropy based classification scheme for land applications of polarimetric SAR," IEEE Trans. Geosci. Remote Sens. 35, 68-78 (1997).

52. A. Freeman and S. L. Durden, "A three-component scattering model for polarimetric SAR data," IEEE Trans. Geosci. Remote Sens. 36, 963-973 (1998).

53. G. Cookmartin et al., "Modeling microwave interactions with crops and comparison with ERS-2 SAR observations," IEEE Trans. Geosci. Remote Sens. 38, 658-670 (2000).

54. J. W. Cable et al., "Multi-temporal polarimetric RADARSAT-2 for land cover monitoring in Northeastern Ontario, Canada," Remote Sens. 6, 2372-2392 (2014).

55. H. Yang et al., "Potential of fully polarimetric SAR data for crops biophysical parameters retrieval," in 2012 First Int. Conf. on Agro-Geoinformatics, pp. 1-5 (2012).

Julie Betbeder received the MS degree in environmental engineering from the Ecole Supérieure d'Agriculture, France (2010) and the PhD degree in geography from the University of Rennes, in 2015. She is actually a Postdoctoral researcher at the Centre d'Etude Spatiale de la BIOsphère (CESBIO) Toulouse, France. Her research activities are devoted to the evaluation of the assimilation of optical and SAR data into agro-meteorological model for crop yield estimation.

Remy Fieuzal received the MS degree in ecology, biostatistics, and modeling and the $\mathrm{PhD}$ degree in remote sensing and agronomy from the University Paul Sabatier, in 2007 and 2013 respectively. His PhD work was on the contributions of satellite radar data for estimating biophysical parameters of agricultural land. He is working on image processing and analysis of satellite data acquired in optical and microwave domains, with the Centre d'Etudes Spatiales de la BIOsphère, Toulouse, France.

Yannick Philippets received in 2013 the master of engineering degree from École Nationale des Sciences Géographiques, Marne-la-Vallée, France, in geomatics and remote sensing applied to environment, then in 2014 the MSc degree in physics processing in remote sensing from Université Pierre-et-Marie-Curie Paris 6, France. He is currently a $\mathrm{PhD}$ student for the French Atomic Energy Commission (CEA) and the French Aerospace Lab (ONERA) about industrial aerosols plume detection algorithms for hyperspectral remote sensing.

Laurent Ferro-Famil received the MS degree in electronic systems and computer engineering, and the PhD degree from the University of Nantes, France, in 1996, 1996, and 2000, respectively. Since 2011 he is a full professor with the University of Rennes 1, France, where he is currently the head of the Remote Sensing department, within the Institute of Electronics and Telecommunications. He is particularly interested in polarimetric SAR and PolInSAR data and radar polarimetry theory.

Frederic Baup received the MS degree in microwaves and optical telecommunications in 2003, and the $\mathrm{PhD}$ degree in SAR remote sensing from the University Paul Sabatier, Toulouse, France, in 2007. Since 2008, he is a researcher in microwave remote sensing with the Centre d'Etudes Spatiales de la BIOsphère Laboratory, Toulouse, France. His research interests include microwave remote sensing applied to land surfaces and SAR image analysis to monitor spatiotemporal variations of soil and vegetation. 